\title{
Quality of life and cost consequence of delays in endovascular treatment for acute ischemic stroke in China
}

\author{
Weiyi Ni ${ }^{1}$, Wolfgang G. Kunz ${ }^{2}$, Mayank Goyal ${ }^{3}$, Lijin Chen $^{4}$ and Yawen Jiang ${ }^{5^{*}}$ (D)
}

\begin{abstract}
Background: Although endovascular therapy (EVT) improves clinical outcomes in patients with acute ischemic stroke, the time of EVT initiation significantly influences clinical outcomes and healthcare costs. This study evaluated the impact of EVT treatment delay on cost-effectiveness in China.

Methods: A model combining a short-term decision tree and long-term Markov health state transition matrix was constructed. For each time window of symptom onset to EVT, the probability of receiving EVT or non-EVT treatment was varied, thereby varying clinical outcomes and healthcare costs. Clinical outcomes and cost data were derived from clinical trials and literature. Incremental cost-effectiveness ratio and incremental net monetary benefits were simulated. Deterministic and probabilistic sensitivity analyses were performed to assess the robustness of the model. The willingness-to-pay threshold per quality-adjusted life-year (QALY) was set to $¥ 71,000(\$ 10,281)$.
\end{abstract}

Results: EVT performed between 61 and 120 min after the stroke onset was most cost-effective comparing to other time windows to perform EVT among AIS patients in China, with an ICER of $¥ 16,409 /$ QALY (\$2376) for performing EVT at 61-120 min versus the time window of 301-360 min. Each hour delay in EVT resulted in an average loss of 0.45 QALYs and 165.02 healthy days, with an average net monetary loss of $¥ 15,105$ (\$2187).

Conclusions: Earlier treatment of acute ischemic stroke patients with EVT in China increases lifetime QALYS and the economic value of care without any net increase in lifetime costs. Thus, healthcare policies should aim to improve efficiency of pre-hospital and in-hospital workflow processes to reduce the onset-to-puncture duration in China.

Keywords: Cost-effectiveness, Acute ischemic stroke, Endovascular treatment

\section{Background}

The healthcare system in China faces a hefty burden of stroke. The age-standardized prevalence of stroke in China were 1114.8 per 100, 000 individuals. Stroke is also one of the leading causes of death in China, accounting for 1.57 million deaths in 2018. Among all type of strokes including acute ischemic stroke (AIS),

\footnotetext{
* Correspondence: jiangyw26@mail.sysu.edu.cn

${ }^{5}$ School of Public Health (Shenzhen), Sun Yat-sen University, Room 215,

Mingde Garden \#6, Sun Yat-sen University, 132 East Outer Ring Road, Panyu District, Guangzhou, Guangdong, China

Full list of author information is available at the end of the article
}

intracerebral hemorrhage and subarachnoid hemorrhage, AIS took almost 82\% [1].

Clinical efficacy of EVT in the treatment of AIS has been demonstrated compared to intravenous thrombolysis (IVT) in improving mortality rates and functional outcomes among patients with AIS, and further influences post-stroke care in the long-term [2-7]. According to previous studies the outcomes of EVT are timedependent and decline with increasing delay between stroke onset and initiation of EVT [8]. As such, the treatment guidelines in China recommend EVT in AIS patients within $6 \mathrm{~h}$ of symptom onset [1]. 
However, significant delays of treatment to AIS patients are present in most of healthcare systems and has a fundamental negative impact on outcomes from both clinical and economic perspective. Recently, two studies investigated the health-related quality of life and cost consequences of delays for stroke patients in the US and Singapore, respectively. The US-based study demonstrated that every hour of treatment delay in EVT reduced a patient's quality-adjusted life years (QALY) by 0.77 [9] and the Singapore study showed AIS patients treated with EVT at early time window had higher quality-adjusted life year (QALY) and less long-term healthcare costs [10]. Similar study had also been conducted in Italy, which documented the cost-effectiveness of EVT for the treatment of AIS patients [11]. However, such evidence is still lacking among Chinese AIS patients. Since cost-effectiveness profiles not only depend on treatment efficacy but also vary across institutional contexts such as local costs of procedures and other treatments, the conclusions from studies conducted in other countries and regions are not directly applicable to the Chinese setting. Moreover, as the Hospital Quality Monitoring System data showed, the rate of AIS patients treated with EVT in 2018 was only 2.81\%, which is mainly because of the higher cost of EVT comparing to the alternative treatments. Hence, it is meaningful to conduct a cost-effectiveness analysis of delay of EVT in China so that the decision makers can have a better insight on the consequence of EVT. The purpose of the present study was to analyze the impact of delay in EVT on healthcare costs and QALYs on the population in Chinese and determine its cost-effectiveness within different time windows of symptom onset.

\section{Methods}

\section{Model overview}

A Markov health state transition model was constructed using (TreeAge Pro 2018, TreeAge, Willliamstown, MA) to compare six treatment time windows among a basecase cohort of patients with AIS aged 66 [1]. Outcomes within treatment initiation time windows of $61-120 \mathrm{~min}$, 121-180 min, 181-240 min, 241-300 min, 301-360 min, and 361-420 min from onset were simulated over a lifetime horizon. Incremental cost-effectiveness ratios (ICER) defined as incremental costs/QALY and net monetary benefit (NMB) were calculated to evaluate cost-effectiveness. We used a willingness-to-pay (WTP) threshold of $¥ 71,000$ per QALY (US\$10,280/ QALY), which is the 2019 gross domestic product (GDP) per capita in China [12].

\section{Model structure and inputs}

A short-term decision tree model was created to analyze acute healthcare costs during index AIS stroke hospitalization. Figures 1A-D detail the structure of the model chronologically. We assigned patients to receive either EVT or non-EVT treatment based on the probability of eligibility for EVT at different treatment initiation time windows. Treatment eligibility probabilities for the overall study population and patient subgroups were extracted from the HERMES collaboration's metaanalysis of patient-level data from the five major randomized controlled trials (RCTs) (MR CLEAN, ESCAPE, REVASCAT, SWIFT PRIME, and EXTEND IA) [2]. EVT eligibility was assumed as $100 \%$ for patients presenting within $2 \mathrm{~h}$ of symptom onset, and then decreased by $3 \%$ every 30 -min delay; this was a conservative assumption based on expert consensus review of the existing literature (Table 1) [2]. To account for patients who received IVT, the acute treatment costs implied in both EVT and non-EVT strategies were adjusted by the percentage of patients receiving IVT from clinical trials [8]. After treatment assignment, patients entered 1 of the 7 possible health states according to the degree of disability as assessed by the modified Rankin Scale (mRS) score of 0 to 6 . The mRS score was further used to calculate healthcare costs.

Based on simulated 90-day $\mathrm{mRS}$ in the short-term model, patients entered the long-term Markov model to simulate outcomes over a lifetime horizon, using a 1year cycle-length. The combination of a short-term model with a long-term model combined the data from the short-term outcomes derived from recent RCTs with additional data from long-term observational studies.

During each cycle of the Markov model, patients could remain in the same health state, experience a recurrent stroke, or die from either age-specific mortality or excess mortality due to history of stroke. Given that the rate of recurrent stroke rate is age-dependent, we implemented yearly recurrent stroke rates following the index stroke based on a stroke registry [14]. The total healthcare costs for each patient were the sum of the short-term healthcare costs after index AIS and lifetime healthcare costs. Recurrent stroke rates with corresponding mRS scores were obtained from the study by Pennlert et al. [14]. The age-specific death rate was drawn from the China Life Table [15]. Excess mortality risk due to stroke was incorporated in the model as the hazard rate ratio for each mRS health state obtained from a global clinical study [16], relative to age-matched controls without AIS in the general population (Table 1).

\section{Costs}

All costs are reported in 2019 Chinese Yuan (¥). Both the short-term and long-term healthcare costs by mRS score were from China National Stroke Registry (CNSR) [17]. The costs of EVT and IVT were based on Endovascular therapy for Acute Ischemic Stroke Trial (EAST) 


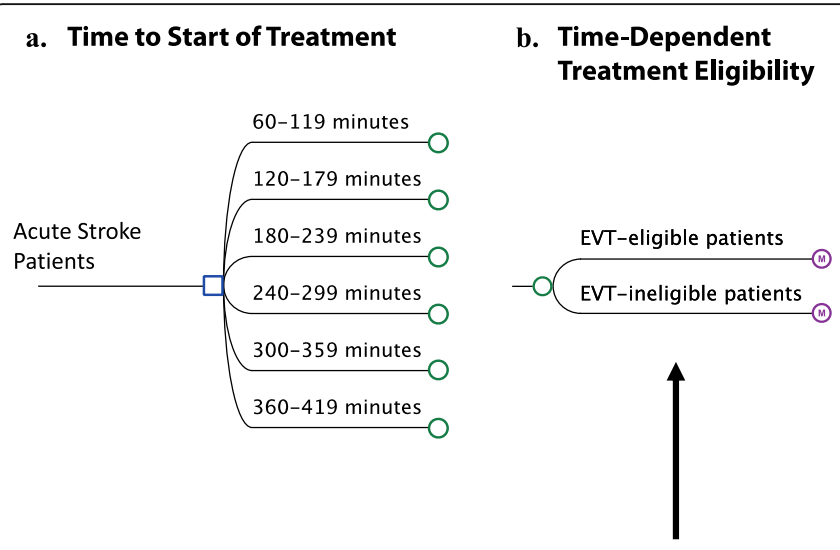

Eligibility Decay c. Health States

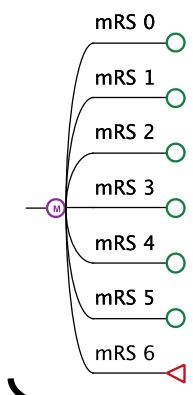

\section{Lifetime Horizon} Recurrent stroke event

Fig. 1 Model Structure Acute ischemic stroke patients in China entered the model-based analysis (A), received either EVT or non-EVT treatment based on the eligibility rate at different treatment initiation time windows (B), and entered a health state based on the modified Rankin Scale (mRS) score at 90 days (C). During each one-year cycle of Markov model, patients remained in the same health state, experienced a recurrent stroke, or died from either age-specific mortality or excess mortality due to stroke (D)

Table 1 Clinical Input Parameters

\begin{tabular}{|c|c|c|c|}
\hline Model Input & Base-Case Value & Range for Sensitivity Analysis & Reference \\
\hline \multicolumn{4}{|l|}{ Initial Probabilities } \\
\hline $\begin{array}{l}\text { For each health state mRS 0-6 } \\
\text { among EVT-treated patients }\end{array}$ & $\begin{array}{l}\text { 90-day mRS distribution } \\
\text { for different times to EVT }\end{array}$ & $\begin{array}{l}\text { Adjusted by distribution } \\
\text { according to sample size }\end{array}$ & HERMES Data $[2,8]$ \\
\hline $\begin{array}{l}\text { For each health state mRS 0-6 } \\
\text { among EVT-ineligible patients }\end{array}$ & $\begin{array}{l}\text { 90-day mRS distribution of } \\
\text { ASPECTS 0-5 control arm }\end{array}$ & $\begin{array}{l}\text { Adjusted by distribution } \\
\text { according to sample size }\end{array}$ & HERMES Data $[2,8]$ \\
\hline \multicolumn{4}{|l|}{ EVT Eligibility by Time } \\
\hline $61-120 \mathrm{~min}$ & 1 & $0.90-1.00$ & \multirow{5}{*}{$\begin{array}{l}\text { Boulouis et al. [13] anc } \\
\text { expert consensus }\end{array}$} \\
\hline $121-180 \mathrm{~min}$ & 0.94 & $0.84-1.00$ & \\
\hline $181-240 \mathrm{~min}$ & 0.88 & $0.78-0.98$ & \\
\hline $241-300 \mathrm{~min}$ & 0.82 & $0.72-0.92$ & \\
\hline $301-360 \mathrm{~min}$ & 0.76 & $0.66-0.86$ & \\
\hline \multicolumn{4}{|l|}{ IVT Eligibility } \\
\hline EVT Patients & 0.83 & $0.82-084$ & \multirow[t]{2}{*}{ HERMES Data [2] } \\
\hline Non-EVT Patients & 0.88 & $0.87-0.89$ & \\
\hline \multicolumn{4}{|l|}{ Transition Probabilities } \\
\hline Recurrent stroke rate & Time-dependent values & $0.044-0.082$ & Pennlert et al. [14] \\
\hline Annual death rate of population & Age-dependent values & N/A & China Life Table [15] \\
\hline \multicolumn{4}{|c|}{ Death hazard ratio by $\mathrm{mRS}$, relative to general age-matched population } \\
\hline mRS 0 & 1.54 & $1.21-1.84$ & \multirow[t]{6}{*}{ Hong et al. [16] } \\
\hline mRS 1 & 1.54 & $1.21-1.84$ & \\
\hline mRS 2 & 2.18 & $1.58-1.69$ & \\
\hline mRS 3 & 3.18 & $1.58-1.69$ & \\
\hline mRS 4 & 4.56 & $2.37-3.03$ & \\
\hline mRS 5 & 6.56 & $3.83-6.44$ & \\
\hline
\end{tabular}

mRS Distribution

mRS after recurrent stroke

d. Clinical Events during Long-Term Follow-Up

Death due to age-specific mortality of the general population

Death due to excess mortality of stroke survivors over the general population

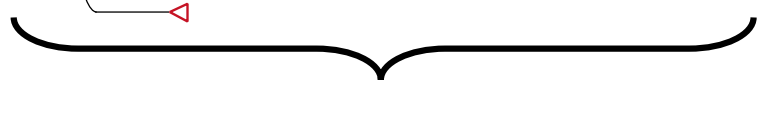


and Thrombolysis Implementation and Monitor of Acute Ischemic Stroke in China (TIMS-CHINA) [17]. All costs were discounted by $3 \%$ each year (Table 2 ) [19].

\section{Utilities}

Cumulative outcomes of alternative therapeutic courses were measured by quality-adjusted life years (QALYs). Utility weights were derived from a study by Ali et al. including stroke patients from Asian countries [18]. Utility values ranged from 0.15 for patients with an mRS of 5 to 0.92 for those with an mRS of 0 (Table 2). All QALYs were discounted at an annual rate of 3\% [19].

\section{Cost-effectiveness analysis}

Cost-effectiveness was compared in terms of ICERs and INMB. The ICER was calculated as incremental costs divided by incremental QALYs. INMB rearranges the ICER and incorporates a WTP per QALY in China, which was set to $\$ \$ 71,000$ per QALY. Generally, a positive INMB value suggests that the intervention should be adopted per the health system's WTP threshold.

\section{Sensitivity analysis}

We used deterministic sensitivity analyses to test the robustness of the model results. Deterministic one-way sensitivity analysis was performed to identify variables that significantly influence the modeled outcomes. Input ranges for deterministic sensitivity analysis were determined by the $95 \%$ confidence interval of the initial probabilities, utilities, and costs (Table 1 and Table 2). A probabilistic sensitivity analysis was also undertaken to evaluate the robustness of base-case results in the presence of simultaneous variability of the input variables. We assumed that the costs followed a gamma distribution, death hazard ratio followed a log-normal distribution, and probabilities and eligibility rates followed a beta distribution. The simulation was run 10,000 times.

As a modeling exercise based on simulation, this study did not require Institutional Review Board approval as the input parameters for this modeling study were obtained from published literature and expert opinion, in which patient-identifiable information was not available. No primary clinical data were collected for this study. The study was reported according to the Consolidated Health Economic Evaluation Reporting Standards (CHEERS) statement [20].

\section{Results}

Base case analysis

Based on simulated outcomes from the six time windows in our model, EVT performed in the earlier time window was associated with more life-time QALYs and higher total healthcare costs. Based on the increasing order of simulated costs, EVT initiated within 301-360 min was associated an ICER of $¥ 15,712$ in relation to the time window of $361-420 \mathrm{~min}$. The time windows of 241-300 min, 181-240 min and 121-180 min were extendedly dominated by the time window of $61-120 \mathrm{~min}$ because the ICERs of the three time windows were

Table 2 Healthcare Costs and Utilities

\begin{tabular}{|c|c|c|c|c|}
\hline & Costs/Utility & Lower Boundary & Upper Boundary & Reference \\
\hline \multicolumn{5}{|c|}{ Acute 90-day Healthcare Costs; by 90 -day mRS } \\
\hline mRS 0-2 & $¥ 11,314$ & $¥ 11,147$ & $¥ 11,483$ & CNSR [17] \\
\hline mRS 3-5 & $¥ 15,448$ & $¥ 15,109$ & $¥ 15,792$ & \\
\hline mRS 6 & $¥ 12,513$ & $¥ 11,499$ & $¥ 13,594$ & \\
\hline \multicolumn{5}{|c|}{ Long-Term Annual Healthcare Costs; by 90 -day mRS } \\
\hline mRS 0-2 & $¥ 8310$ & $¥ 8052$ & $¥ 8573$ & CNSR \\
\hline mRS 3-5 & $¥ 12,771$ & $¥ 11,499$ & $¥ 13,594$ & \\
\hline Additional Cost of IVT & $¥ 68,436$ & $¥ 58,864$ & $¥ 79,115$ & EAST [17] \\
\hline Additional Cost of EVT & $¥ 12,579$ & $¥ 11,877$ & $¥ 13,310$ & CNSR, TIMS-CHINA [17] \\
\hline Cost of Recurrent Stroke & $¥ 15,448$ & $¥ 15,109$ & $¥ 15,792$ & EAST [17] \\
\hline \multicolumn{5}{|l|}{ Utilities; by 90 -day mRS } \\
\hline mRS 0 & 0.92 & 0.88 & 0.96 & Ali et al. [18] \\
\hline mRS 1 & 0.84 & 0.81 & 0.87 & \\
\hline mRS 2 & 0.74 & 0.70 & 0.78 & \\
\hline mRS 3 & 0.58 & 0.53 & 0.63 & \\
\hline mRS 4 & 0.37 & 0.32 & 0.42 & \\
\hline mRS 5 & 0.15 & 0.11 & 0.19 & \\
\hline
\end{tabular}

All costs are in Chinese Yuan. EVT endovascular treatment, IVT intravenous thrombolysis, mRS modified Rankin Scale 
larger than the ICER of the latter when comparing with the time window of 301-360 min. Moreover, the ICER of time window of $61-120$ vs. $301-360$ was $¥ 16,409$. Hence, initiation of EVT between 61 and 120 min was most cost-effective among all the time windows when using once the GDP per capita as the threshold of WTP per QALY (Table 3). Each hour delay in initiating EVT resulted in an average loss of 0.45 QALYs and 165.02 healthy days (Table 4). Consequently, the average net monetary loss per hour due to delay in EVT treatment was estimated at $¥ 15,105$ (Table 4).

\section{Sensitivity analysis}

The results of the deterministic one-way sensitivity analysis are presented in Fig. 2. The time windows of 61$120 \mathrm{~min}$ and 301-360 min were compared when the input parameters were varied within pre-specified ranges. The ICER comparison between the 61-120 min and 301-360 min time windows ranged from approximately $¥ 15,000$ to $¥ 18,000$ for all deterministic sensitivity results (horizontal bars in Fig. 2). Based on the once the GDP per capita WTP threshold, treatment initiated within 61-120 min of stroke onset was the cost-effective option in reference to the 301 to $360 \mathrm{~min}$ alternative. More, the outcomes demonstrated that ICER was most sensitive to the additional costs of EVT.

The probabilistic sensitivity analysis also illustrated that EVT treatment within $61-120$ min after the stroke onset was the cost-effective strategy in $84.8 \%$ of simulations at the once the GDP per capita WTP threshold (Fig. 3). This increased to $87.8 \%$ at a WTP threshold of three times of GDP per capita at $¥ 213,000$.

\section{Discussion}

This study investigated the lifetime consequences of delayed initiation of EVT after stroke onset in terms of health-related quality of life and costs of EVT from the China healthcare perspective. Initiating EVT within 61120 min after symptom onset was shown to be most cost-effective. We applied input parameters specific to the AIS patients in China, with both short- and longterm costs as well as utilities. The evidence of clinical benefit of EVT does not necessarily warrant its costeffectiveness without considering its impact on healthcare costs, and it is essential for policymakers and clinicians to determine whether the benefits of EVT outweighs the higher cost of EVT compared to alternative treatments. The current study demonstrates that despite the higher short-term healthcare costs of EVT, EVT generated more QALYs, and is most cost-effective at earlier time windows after symptom onset.

Our findings are similar to those reported in costeffectiveness studies of EVT in both the US and Singapore setting. In the US, each hour of delay in EVT resulted in an average loss of 0.77 QALYs and increased the healthcare cost by US\$6173/QALY [9]. The Singapore study demonstrated earlier treatment with EVT was cost-effective, when the threshold of WTP per QALY was SG\$36,500 [10]. Previous studies also showed with EVT and IVT was associated with lower disability at 90 days after stroke compared to IVT alone [8], with every of hour of delay in EVT reducing the absolute risk difference for good outcome by $6 \%$ [21]. However, those results could not be directly adopted to the China AIS patients, because the healthcare system and patient preferences to health states were different than either the US or Singapore. Hence, the current study is first to investigate the delay of EVT to AIS patient from China healthcare perspective to our knowledge.

The total healthcare costs associated with the 61120 min subgroup were higher versus patients treated at later time points. This was driven by the greater proportion of patients eligible for EVT at the earlier time window and, therefore, a greater proportion of patients incurring costs of EVT relative to the less expensive alternatives. Patients with EVT have higher probability of improved functional outcome (lower mRS score), which is likely to reduce long-term costs associated with nursing home or home help relative to the alternative treatments, although the reduction in costs cannot fully offset the additional costs from EVT. Similar to our findings, Pan et al. reported EVT was associated with higher lifetime costs compared to IVT alone [17]. In spite of the greater initial treatment-related costs, EVT was

Table 3 Results of Cost-Effectiveness Analyses of Time Delays in EVT Treatment

\begin{tabular}{lllllll}
\hline Time Window of EVT Initiation & Cost & Incremental Cost & QALY & Incremental QALY & ICER & INMB \\
\hline $361-420 \mathrm{~min}$ & $¥ 120,285$ & & 2.45 & & & \\
$301-360 \mathrm{~min}$ & $¥ 128,225$ & $¥ 7940$ & 2.95 & 0.51 & $¥ 15,712$ & Extended domination \\
$241-300 \mathrm{~min}$ & $¥ 137,671$ & $¥ 9447$ & 3.42 & 0.46 & Extended domination \\
$181-240 \mathrm{~min}$ & $¥ 140,133$ & $¥ 2462$ & 3.57 & 0.15 & Extended domination \\
$121-180 \mathrm{~min}$ & $¥ 150,357$ & $¥ 10,224$ & 4.19 & 0.62 & $¥$ \\
$61-120 \mathrm{~min}$ & $¥ 158,616$ & $¥ 8259$ & 4.81 & 0.61 & $¥ 16,409$ & $¥ 101,106$ \\
\hline
\end{tabular}

EVT endovascular therapy, QALY quality-adjusted life-years, ICER incremental cost-effectiveness ratio, INMB incremental net monetary benefit 
Table 4 QALY, Healthy Life Days, and NMB Loss by Time

\begin{tabular}{ll}
\hline Items & Measurement \\
\hline Average QALY per minute & 0.0075 \\
Average QALY per hour & 0.45 \\
Average Healthy Life days per minute (day) & 2.75 \\
Average Healthy Life days per hour (day) & 165.02 \\
Average NMB per minute (¥) & 252 \\
Average NMB per hour $(¥)$ & 15,105 \\
\hline
\end{tabular}

found to be cost effective in previous costeffectiveness studies performed in both western and eastern countries [17, 22-28].

Moreover, we simulated six different treatment windows in the current study to demonstrate the costeffectiveness. In reality, clinicians may not be free to choose when to treat because the time from onset to puncture depends on many factors, such as patient transportation, accessibility of EVT at hospitals and affordability. Our findings that earlier treatment of EVT is more cost-effective may provide supportive evidence from the economic perspective to healthcare decision makers on improving the delay to perform EVT on AIS patients in China.

The current study has several limitations. First, annual healthcare costs for patient survived from AIS was applied for long-term costs. It is possible that the healthcare costs incurred in the first 2 years post-stroke was greater than those in subsequent years. However, this time-variant disease burden was not reflected in the current input parameters. To partially address this limitation, we performed a deterministic sensitivity analysis on annual healthcare costs. Second, the current model was constructed from the China healthcare perspective, which did not account for indirect costs related to potential productivity loss. However, given the majority of stroke population consisted of patients with advanced age, indirect costs would likely contribute far less than the direct healthcare costs in the present study. Moreover, similarly to other economic modeling studies, conclusions from the current study are region-specific and typically are not directionally applicable to other regions given specific medical costs, health utility preferences, and WTP thresholds vary. For example, the management and financing of healthcare facilities in European countries could be drastically different from those in China [29-33]. The direct costs of EVT spread over a wide range across countries as of $\$ 14,544$ in the US [26], $\$ 3000$ in Singapore [10] and $\$ 1980$ in China. Future local adaptations to additional regions using the model presented herein would provide more specifics on local ICER values and a more precise local time window in

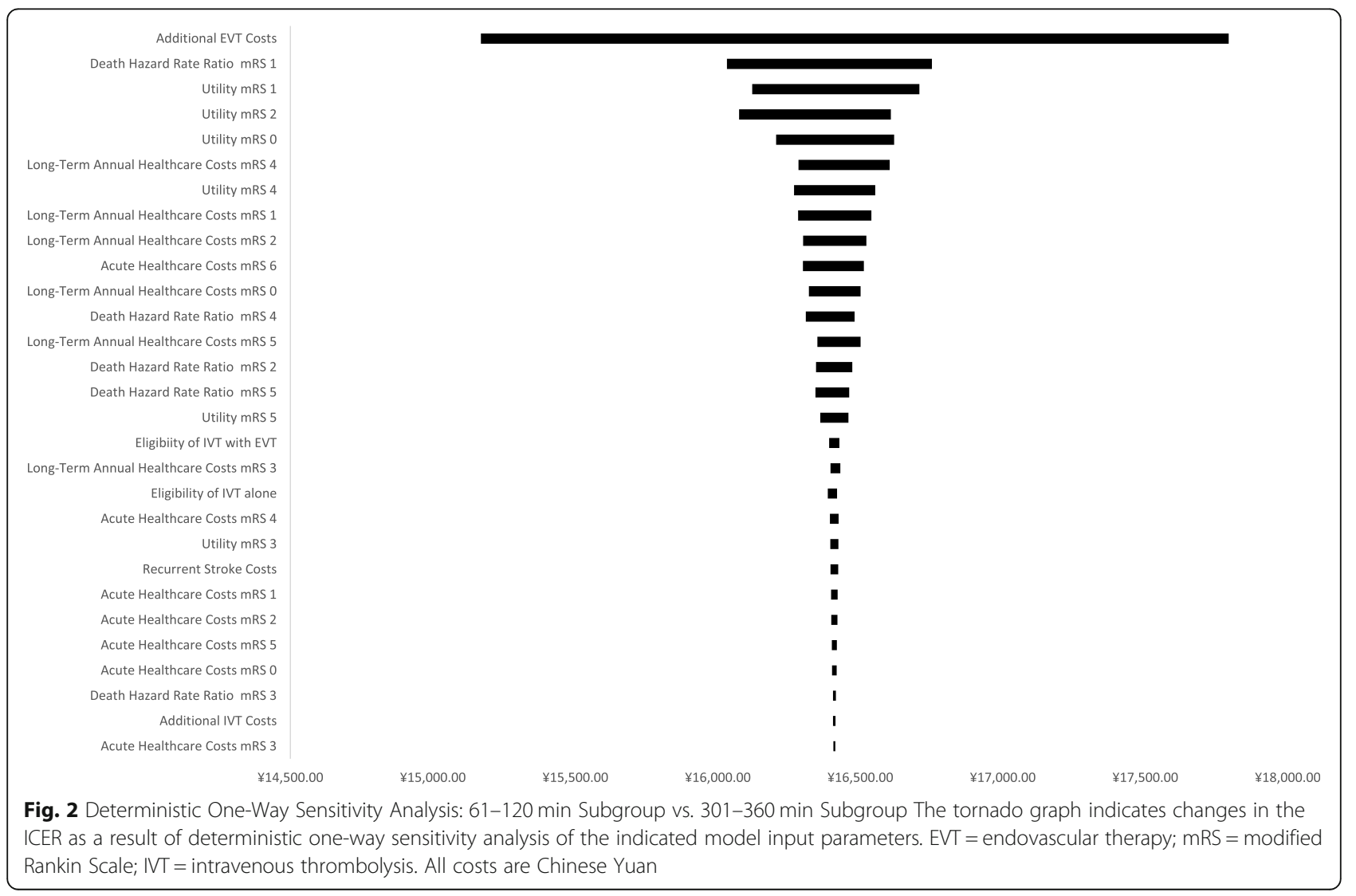




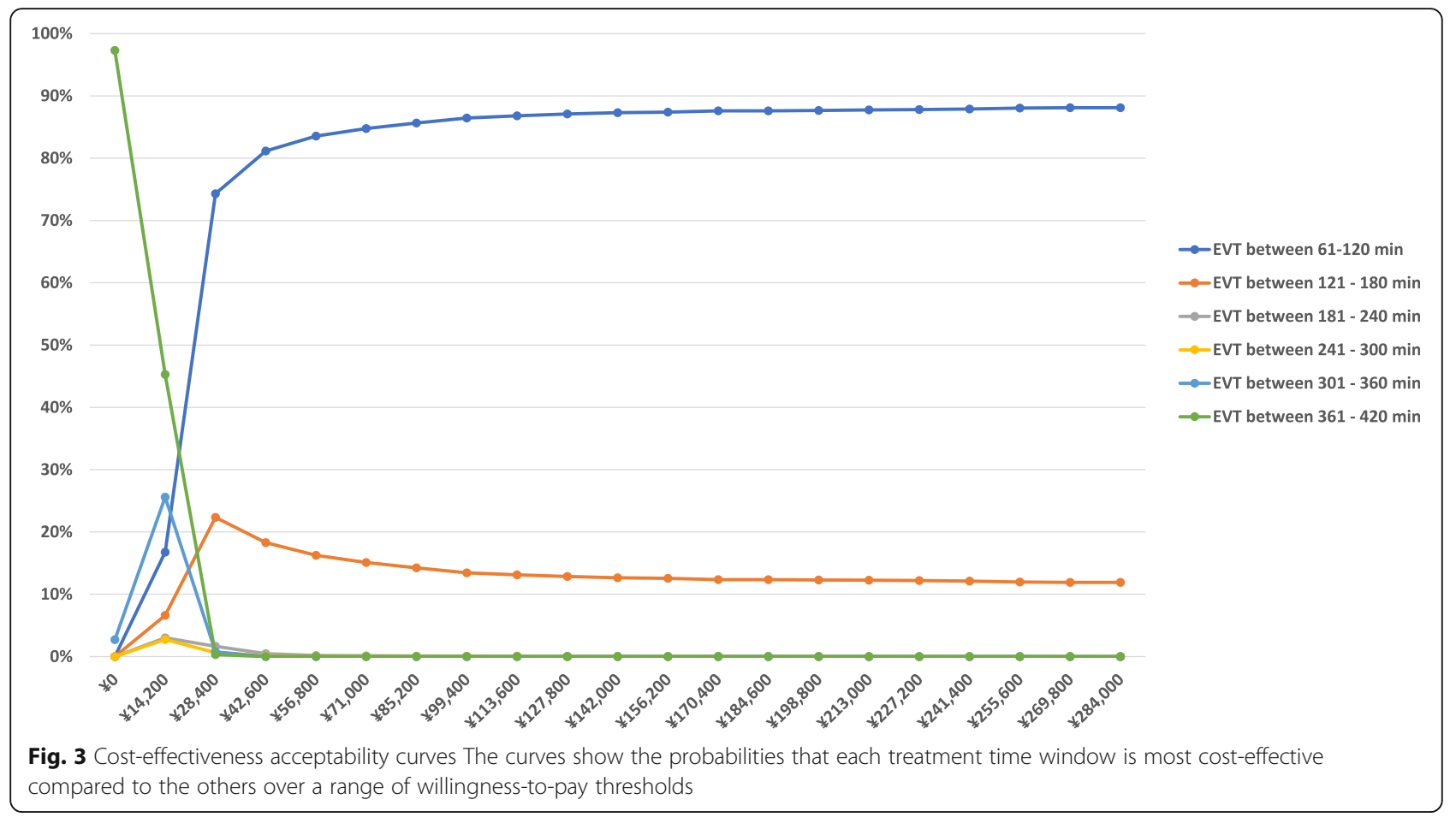

which treatment with EVT is no longer considered costeffective. Finally, preventive remedies to AIS may change the occurrence rate of AIS among Chinese population, which is not covered by current modeling. The costeffectiveness of preventive treatments in China may worth an stand-alone study.

\section{Conclusions}

This study indicates that performing EVT at earlier time windows is more cost-effective compared to initiating treatment at a later time after stroke onset from the China healthcare system perspective. Healthcare policies in China need to be implemented to improve efficiency of pre-hospital and in-hospital workflow processes to reduce the time to perform EVT on AIS patients.

\section{Abbreviations}

AIS: Acute ischemic stroke; CNSR: China National Stroke Registry;

EVT: Endovascular therapy; GDP: Gross domestic product; ICER: Incremental cost-effectiveness ratio; INMB: Incremental net monetary benefit:

IVT: Intravenous thrombolysis; mRS: modified Rankin Scale; QALY: Qualityadjusted life-year: RCT: Randomized controlled trial; TIMS-

CHINA: Thrombolysis Implementation and Monitor of Acute Ischemic Stroke in ChinaWTPWillingness-to-pay

\section{Acknowledgements}

N/A.

\section{Authors' contributions}

Concept and overall approach: WN, WK, MG, LC and YJ; data collection: WN, LC and YJ; analysis and interpretation: WN, WK, MG, LC and YJ; drafting the manuscript: $W N$ and $Y J$; reviewing and revising the manuscript: $W N$, WK, MG, LC and YJ. The author(s) read and approved the final manuscript.
Funding

The National Natural Science Foundation of China (72004242).

\section{Availability of data and materials}

All model inputs related to this study can be found within the article and tables. The full TreeAge model has been provided for editorial and peer review and can be obtained from the corresponding author upon reasonable requests.

\section{Declarations}

Ethics approval and consent to participate

The analysis was only based on published results. Thus, an ethical approval of consent to participate was not necessary.

\section{Consent for publication}

$\mathrm{N} / \mathrm{A}$

\section{Competing interests}

WN owns Medtronic stock. MG is a consultant of Medtronic, Stryker, Microvention, entice, and GE Healthcare.

\section{Author details}

'Department of Pharmaceutical and Health Economics, University of Southern California, Los Angeles, California, USA. ²Department of Radiology, University Hospital, LMU Munich, Munich, Germany. ${ }^{3}$ Departments of Radiology and Clinical Neurosciences, University of Calgary, Calgary, Alberta, Canada. ${ }^{4}$ Chronic Disease Research Institute, School of Public Health,

Zhejiang University School of Medicine, Hangzhou, Zhejiang, China. ${ }^{5}$ School of Public Health (Shenzhen), Sun Yat-sen University, Room 215, Mingde Garden \#6, Sun Yat-sen University, 132 East Outer Ring Road, Panyu District, Guangzhou, Guangdong, China.

Received: 12 December 2020 Accepted: 22 December 2021 Published online: 06 January 2022

\section{References}

1. Pan F, Ye T, Sun P, Gui S, Liang B, Li L, Zheng D, Wang J, Hesketh RL, Yang L et al. Time Course of Lung Changes On Chest CT During Recovery From 
2019 Novel Coronavirus (COVID-19) Pneumonia. 2020, Published online on Feb 13, 2020(0):200370.

2. Goyal M, Menon BK, van Zwam WH, Dippel DW, Mitchell PJ, Demchuk AM, et al. Endovascular thrombectomy after large-vessel ischaemic stroke: a meta-analysis of individual patient data from five randomised trials. Lancet. 2016;387(10029):1723-31. https://doi.org/10.1016/S0140-6736(16)00163-X.

3. Berkhemer OA, Fransen PS, Beumer D, van den Berg LA, Lingsma HF, Yoo $\mathrm{AJ}$, et al. A randomized trial of intraarterial treatment for acute ischemic stroke. N Engl J Med. 2015;372(1):11-20. https://doi.org/10.1056/ NEJMoa1411587.

4. Campbell BC, Mitchell PJ, Kleinig TJ, Dewey HM, Churilov L, Yassi N, et al. Endovascular therapy for ischemic stroke with perfusion-imaging selection. N Engl J Med. 2015;372(11):1009-18. https://doi.org/10.1056/NEJMoa1414792.

5. Goyal M, Demchuk AM, Menon BK, Eesa M, Rempel JL, Thornton J, et al. Randomized assessment of rapid endovascular treatment of ischemic stroke. N Engl J Med. 2015;372(11):1019-30. https://doi.org/10.1056/ NEJMoa1414905.

6. Jovin TG, Chamorro A, Cobo E, de Miquel MA, Molina CA, Rovira A, et al. Thrombectomy within 8 hours after symptom onset in ischemic stroke. $\mathrm{N}$ Engl J Med. 2015;372(24):2296-306. https://doi.org/10.1056/NEJMoa1503780.

7. Saver JL, Goyal M, Bonafe A, Diener HC, Levy El, Pereira VM, et al. Stentretriever thrombectomy after intravenous t-PA vs. t-PA alone in stroke. $\mathrm{N}$ Engl J Med. 2015;372(24):2285-95. https://doi.org/10.1056/NEJMoa1415061.

8. Saver JL, Goyal M, van der Lugt A, Menon BK, Majoie CB, Dippel DW, et al. Time to treatment with endovascular Thrombectomy and outcomes from ischemic stroke: a Meta-analysis. Jama. 2016;316(12):1279-88. https://doi. org/10.1001/jama.2016.13647.

9. Kunz WG, Hunink MG, Almekhlafi MA, Menon BK, Saver JL, Dippel DWJ, et al. Public health and cost consequences of time delays to thrombectomy for acute ischemic stroke. Neurology. 2020;95(18):e2465-75. https://doi.org/1 0.1212 WNL.0000000000010867.

10. Ni W, Kunz W, Goyal M, Ng YL, Tan K, De Silva DA. Lifetime quality of life and cost consequences of delays in endovascular treatment for acute ischaemic stroke: a cost-effectiveness analysis from a Singapore healthcare perspective. BMJ Open. 2020;10(9):e036517. https://doi.org/10.1136/ bmjopen-2019-036517.

11. Ruggeri M, Basile M, Zini A, Mangiafico S, Agostoni EC, Lobotesis K, et al. Cost-effectiveness analysis of mechanical thrombectomy with stent retriever in the treatment of acute ischemic stroke in Italy. J Med Econ. 2018;21(9): 902-11. https://doi.org/10.1080/13696998.2018.1484748.

12. http://www.stats.gov.cn/tjsj/zxfb/202002/t20200228_1728913.html. Accessed 01 Oct 2020.

13. Boulouis G, Lauer A, Siddiqui AK, Charidimou A, Regenhardt RW, Viswanathan A, et al. Clinical imaging factors associated with infarct progression in patients with ischemic stroke during transfer for mechanical Thrombectomy. JAMA Neurol. 2017;74(11):1361-7. https://doi.org/10.1001/ja maneurol.2017.2149.

14. Pennlert J, Eriksson M, Carlberg B, Wiklund PG. Long-term risk and predictors of recurrent stroke beyond the acute phase. Stroke. 2014;45(6): 1839-41. https://doi.org/10.1161/STROKEAHA.114.005060.

15. https://apps.who.int/gho/data/?theme=main\%26vid=60340. Accessed 01 Oct 2020.

16. Hong KS, Saver JL. Years of disability-adjusted life gained as a result of thrombolytic therapy for acute ischemic stroke. Stroke. 2010;41(3):471-7. https://doi.org/10.1161/STROKEAHA.109.571083.

17. Pan Y, Cai X, Huo X, Zhao X, Liu L, Wang Y, et al. Cost-effectiveness of mechanical thrombectomy within 6 hours of acute ischaemic stroke in China. BMJ Open. 2018;8(2):e018951. https://doi.org/10.1136/bmjopen-2017018951.

18. Ali M, Maclsaac R, Quinn TJ, Bath PM, Veenstra DL, Xu Y, et al. Dependency and health utilities in stroke: data to inform cost-effectiveness analyses. Eur Stroke J. 2017;2(1):70-6. https://doi.org/10.1177/2396987316683780.

19. Weinstein MC, Siegel JE, Gold MR, Kamlet MS, Russell LB. Recommendations of the panel on cost-effectiveness in health and medicine. JAMA. 1996; 276(15):1253-8. https://doi.org/10.1001/jama.1996.03540150055031.

20. Husereau D, Drummond M, Petrou S, Carswell C, Moher D, Greenberg D, et al. Consolidated health economic evaluation reporting standards (CHEERS) statement. Value Health. 2013;16(2):e1-5. https://doi.org/10.1016/j. jval.2013.02.010.

21. Fransen PS, Berkhemer OA, Lingsma HF, Beumer D, van den Berg LA, Yoo $\mathrm{AJ}$, et al. Time to reperfusion and treatment effect for acute ischemic stroke: a randomized clinical trial. JAMA Neurol. 2016;73(2):190-6. https://doi.org/1 0.1001/jamaneurol.2015.3886.

22. Aronsson M, Persson J, Blomstrand C, Wester P, Levin LA. Cost-effectiveness of endovascular thrombectomy in patients with acute ischemic stroke. Neurology. 2016;86(11):1053-9. https://doi.org/10.1212/WNL. 0000000000002439

23. Arora N, Makino K, Tilden D, Lobotesis K, Mitchell P, Gillespie J. Costeffectiveness of mechanical thrombectomy for acute ischemic stroke: an Australian payer perspective. J Med Econ. 2018;21(8):799-809. https://doi. org/10.1080/13696998.2018.1474746.

24. Ganesalingam J, Pizzo E, Morris S, Sunderland T, Ames D, Lobotesis K. Costutility analysis of mechanical Thrombectomy using stent retrievers in acute ischemic stroke. Stroke. 2015:46(9):2591-8.

25. Kunz WG, Hunink MG, Sommer WH, Beyer SE, Meinel FG, Dorn F, et al. Costeffectiveness of endovascular stroke therapy: a patient subgroup analysis from a US healthcare perspective. Stroke. 2016;47(11):2797-804. https://doi. org/10.1161/STROKEAHA.116.014147.

26. Shireman TI, Wang K, Saver JL, Goyal M, Bonafe A, Diener HC, et al. Costeffectiveness of solitaire stent retriever Thrombectomy for acute ischemic stroke: results from the SWIFT-PRIME trial (solitaire with the intention for Thrombectomy as primary endovascular treatment for acute ischemic stroke). Stroke. 2017:48(2):379-87. https://doi.org/10.1161/STROKEAHA.116.014735.

27. Steen Carlsson K, Andsberg G, Petersson J, Norrving B. Long-term costeffectiveness of thrombectomy for acute ischaemic stroke in real life: an analysis based on data from the Swedish stroke register (Riksstroke). Int J Stroke. 2017;12(8):802-14. https://doi.org/10.1177/1747493017701154.

28. Leppert MH, Campbell JD, Simpson JR, Burke JF. Cost-effectiveness of intraarterial treatment as an adjunct to intravenous tissue-type plasminogen activator for acute ischemic stroke. Stroke. 2015;46(7):1870-6. https://doi. org/10.1161/STROKEAHA.115.009779.

29. Szczygiel N, Rutkowska-Podolska M, Michalski G. Information and Communication Technologies in Healthcare: Still Innovation or Reality? Innovative and Entrepreneurial Value-creating Approach in Healthcare Management. In: 5th Central European Conference in Regional Science CERS, vol. 2014; 2014.

30. Bem A, Michalski G. Hospital profitability vs. selected healthcare system indicators. In: CEFE 2015 - Central European Conference in Finance and Economics: 2015: Technical University of Košice; 2015.

31. Šoltés V, Gavurová B. The functionality comparison of the health care systems by the analytical hierarchy process method. E+M Ekonomie a. Management. 2014;17(3):100-17. https://doi.org/10.15240/tul/001/2014-3-009.

32. Bem A, Siedlecki R, Prędkiewicz P, Gazzola P, Ryszawska B, Ucieklak-Jeż P. Hospitals' Financial Health in Rural and Urban Areas in Poland: Does It Ensure Sustainability? Sustainability. 2019;11(7):1932.

33. Michalski G, Blendinger G, Rozsa Z, Cierniak-Emerych A, Svidronova M, Buleca J, Bulsara H. Debt To Equity Levels in Polish Nonprofit Organisations. Eng Econ. 2018;29(5). https://doi.org/10.5755/j01.ee.29.5.19666.

\section{Publisher's Note}

Springer Nature remains neutral with regard to jurisdictional claims in published maps and institutional affiliations.
Ready to submit your research? Choose BMC and benefit from:

- fast, convenient online submission

- thorough peer review by experienced researchers in your field

- rapid publication on acceptance

- support for research data, including large and complex data types

- gold Open Access which fosters wider collaboration and increased citations

- maximum visibility for your research: over $100 \mathrm{M}$ website views per year

At BMC, research is always in progress.

Learn more biomedcentral.com/submissions 